Article

\title{
Factors Affecting Successful Agricultural Loan Applications: The Case of a South African Credit Provider
}

\author{
Johannes I. F. Henning * $\mathbb{D}$, Dominique A. Bougard, Henry Jordaan $\mathbb{D}$ and Nicolette Matthews $\mathbb{D}$ \\ Department Agricultural Economics, University of the Free State, 205 Nelson Mandela Ave, Bloemfontein 9301, \\ South Africa; dombougard1@gmail.com (D.A.B.); JordaanH@ufs.ac.za (H.J.); MatthewsN@ufs.ac.za (N.M.) \\ * Correspondence: HenningJIF@ufs.ac.za; Tel.: +27-51-401-9713
}

Received: 18 October 2019; Accepted: 7 November 2019; Published: 13 November 2019

check for updates

\begin{abstract}
The purpose of the paper is to determine the influence of different factors used by a formal credit institution to evaluate loan applications in the agricultural sector. The research attempts to capture the actual factors considered by credit institutions rather than the traditional factors found in literature. Loan applications from 128 farmers, predominantly commercial farmers, were obtained from a credit institution with branches situated in various provinces of South Africa. Data consisted of loan application information which is broader than the financial information normally obtained in credit research, and the final decision of the credit provider. Principal component logistic regression was used to investigate the likeliness with which loan application variables influence the outcome of the loan application. Results indicate that loan applications that are more likely to be successful are older more experienced farmers, who can provide sufficient collateral, have more years of business with the credit provider, have an acceptable credit history, request smaller loan amounts, have lower interest expense ratio, higher production cost ratios, and have diversification strategies. This paper contributes to knowledge on information used by financial credit providers (institutions) in classifying agricultural loan applications as successful as guided by actual factors used in credit decision making by the credit provider.
\end{abstract}

Keywords: agricultural finance; principal component analysis; logistic regression; repayment ability; South Africa

\section{Introduction}

Modern agriculture is heavily dependent on debt which is normally provided in the form of credit. Credit permits farmers to assume new investments and technology [1], allowing farmers to increase their productivity and efficiency in agricultural businesses. Financial capital has the ability to improve standards of living, expand capital investment, and provide a social service to farmers. Lending in the agricultural sector has several unique characteristics that influence the financial requirements in the sector [2]. The agricultural sector is regarded as the highest degree of credit risk compared to other sectors in the economy [3]. One of the aspects in the agricultural sector that needs to be considered is the length of production cycles which has an impact on the frequency that payment on loans can be made [2], that could pose as a risk factor for financial institutions. Other reasons for the high risks include various factors such as the seasonal nature of agriculture, climate change, modernised technology, excessive division of agricultural land, perishable nature of agricultural products, fluctuation in demand, and prices for products [3]. Another aspect that plays an important role in the South African agricultural role is the fact that most subsidies in the agricultural sector has been abolished that existed during the apartheid era of the country. These subsidies that, during the apartheid era, assisted in modernising the agricultural sector are no longer available and farmers, 
commercial farmers, cannot rely on such assistance [4]. The impact of these factors ultimately affects the repayment ability of borrowers [3]; hence implying increased risk to credit providers.

Financial institutions are important for the economy as they make credit available to investors who have profitable ideas. Statistics provided by the Department of Agriculture, Forestry, and Fisheries (DAFF) shows that since 2009 on average, 59\% of debt in the agricultural sector is provided by commercial banks [5]. From 2015, the sector received more than $60 \%$ of total debt from commercial banks [5]. This is an indication of the dependence of the agricultural sector on credit from commercial suppliers in South Africa. Credit from the Department of Agriculture has averaged around 0.15\% of total credit since 2009, showing that the department is not really a role player in providing credit to farmers. However, the Land and Agricultural Bank's contribution averaged around $27 \%$ for the same period [5]. Credit is considered as the borrowing capacity provided to a farmer, individual, or institution in the form of a loan. In recent years, formal financial institutions have significantly increased total lending to the South African agricultural sector [6]. Total South African agricultural debt has increased from R36 443.8 million in 2005 to an estimated R158 342 million in 2017 [5]. The increase in agricultural debt is caused by a strong reliance on credit to finance capital investments such as machinery, vehicles, livestock, implements, and land [7]. The rise in demand for credit is caused by an increased demand for capital investment since land and fixed improvements require financial capital in order to use natural resources to their maximum potential. The increase in debt has made credit evaluation more difficult for financial institutions. Therefore, financial institutions have become more aware of the need to improve credit evaluation procedures [8]. Before credit can be granted, farmers undergo a credit evaluation process, which consists of the collection, analysis, and evaluation of information such as credit repayment history, income, and overall financial status [9].

The repayment ability of an applicant can be determined through a subjective or objective approach. The subjective approach is performed on a judgmental basis where a credit analyst determines the creditworthiness of the applicant based on personal knowledge and experience [10]. This approach leads to inaccuracies, high training costs, and inconsistent decisions made by different credit analysts for the same application [10]. The shortcomings associated with the subjective approach may be overcome by using more objective approaches. Objective approaches include statistical models, which are available for credit classification.

The objective approach is a quantitative evaluation technique used by financial institutions to evaluate the credit worthiness of an applicant [11]. Certain personal and business characteristics of the applicant are used in a statistical model to predict the probability of the applicant to be able to repay the loan. As such, this approach provides a credit analyst with an objective tool to assess whether or not credit is to be granted to a particular applicant. The objective approach thus has potential to reduce human judgement, reduce evaluation procedure costs, improve accuracy, improve consistency, and reduce classification errors associated with the subjective approach.

Internationally, researchers have successfully applied neural networks [8,12], decision trees [8], and logistic regression $[8,12,13]$ to determine the factors affecting access to agricultural finance. Of the different methods, a regression framework proved to be the preferred approach [14]. The challenge of the regression framework, however, is that there are various personal and business characteristics of applicants, which may influence their ability to repay the loan. The inclusion of those characteristics as explanatory variables in the model is of great importance, since they have a direct influence on the accuracy of the model.

Inclusion of the correct and subjective variables has the ability to improve performance through increased classification accuracy and greater cost-effectiveness, and it also contributes to a better understanding of the underlying process, which generates the data [15]. The importance of the selection of variables is echoed by Bolton [16] who argues that significant improvements in classification is most likely to come from including new or additional predictive characteristics in credit classifications decisions. The benefit of improving the accuracy of the model through the selection of appropriate variables may be substantial. West [17] states that even a fraction of a percentage increase in credit 
scoring accuracy could be regarded as a significant accomplishment. While such an improvement may not seem large, if considering the number and associated monetary value of credit applicants that are assessed, a small improvement will make a noteworthy contribution in the agricultural credit sector.

The specific information to include in the credit scoring models has received attention from researchers in the past. While, traditionally, financial information is mainly considered in loan applications, there are several other factors, typically non-financial, that also affect the ability of a borrower to repay a loan. Such information includes cyclical performance, seasonal production patterns, farm typography, commodity, geographic location, participation in government programs, leasing farmland, high capital intensity, and annual payments of loans [18,19]. In an attempt to understand the factors used in credit evaluations, Henning and Jordaan [20] employed a Delphi study to investigate the factors used by a financial institution. The results indicated that there are additional factors that are being used in credit evaluations compared to what is generally found in research. The factors are characteristics that influence the decision whether or not to grant credit including age, account standing, type of farming enterprise, client's success factor compared to competitors, farm experience, collateral, credit record, education/qualification, farm ownership, past and current financial information, experience, reputation, product market projections, sustainability of the enterprise, and industry projection risk. Interestingly, information and research related to factors influencing access to credit is often collected from the applicants instead of the financial institutions who provide the credit [20]. The problem is that there could be a mismatch in how applicants see their creditworthiness compared to the view of the credit provider. Ultimately, it is the view of the credit provider that determines whether an application for credit is successful. It is therefore important to understand the factors that financial institutions use to evaluate loan applications in order to gain a better understanding of the requirements that applicants have to meet.

The aim of this research is to determine the different factors used in evaluating loan applications in the agricultural sector by a credit institution. The research explores the factors used by a financial institution as indicated by Henning and Jordaan [20] in granting credit to applicants. The research determines whether factors such as years as client, number of enterprise diversification, credit record, account standings, and associated industry risk do have an impact on the final decision. These factors will be explored in conjunction with other popular factors found in credit research such as age, education, collateral, financial performance, loan amount, and payback period amongst others. The research contributes to literature by expanding on the traditional factors used in literature and therefore provides a better understanding of the factors used by a credit institution to guide decisions on granting credit to farmers. Thus, a better understanding of the complex mechanisms that influence credit decision making is provided which could also assist the applicants to consider factors that could have an impact on the success of their loan applications.

The following section of the paper discusses the method and data used in the research. Firstly, the data collection and a short description is provided which is followed by the procedures in terms of the principal component. A discussion of the factors identified is also presented in the section. The final section of the paper concludes the findings from the research and how the findings can contribute to the agricultural credit industry and suggestions for future research.

\section{Data and Methods}

\subsection{Data}

A formal agreement was reached with a financial institution to provide loan application information from actual applicants. The agreement also stipulated that all data obtained from the institution would remain confidential. Information of 128 loan applications, mostly commercial farmers, were obtained from different areas of South Africa, including: Northern-(Gauteng and Mpumalanga), Central-(Free State, North West and Northern Cape), and Coastal regions (Western Cape, Southern Cape, Eastern Cape and KwaZulu Natal). The applications included crop, livestock (including 
game), horticulture, and mixed farming enterprises. The information was provided in coded form by an executive representative of the financial institution and the research team had no contact with individual clients to ensure anonymity of every client. Permission for the study was granted by an ethics committee (ethical clearance number is UFS-HSD2018/1061).

According to Ogundeji et al. [21] the most common factors used to evaluate access to credit includes: age, farm and non-farm income, financial assets (savings), farm size, family labour, ownership, credit awareness, gender, education and repayment ability. Also mentioned by the authors is that in their case some of the information used in their analysis was not sourced from financial institutions but rather from the applicants. For instance, loan repayment record was sourced from the applicants and not from a financial institutions which could be misleading. An attempt must be made to source the information from the financial institutions which would be able to provide records and reliable information on such factors, which is what makes this study different from previous research. The information obtained from the financial institution was guided by the research from Henning and Jordaan [20,22] and included: purpose of the loan, amount, period of repayment, years as client, account standing, credit history, collateral, financial information, farm diversification (number of enterprises on farm), and industry risk association. Information about the applicant included: ownership of business, age of applicant, years of farming experience, and education. The final decision of the financial institution was also provided and was used as a binary dependent variable, which took on the value of one when an application was approved or zero when rejected. This research thus incorporates a wider set of variables compared to previous research, as guided by Henning and Jordaan [20]. This broader range of variables used were also sourced from a financial institution instead of applicants, which means these were the actual information used in evaluating each of the applications on reliable information as used by the financial institution.

Binary or categorical independent variables were used in the research analysis. The basis for the dummy variables are indicated in bold. Variables were grouped into three categories, namely loan characteristics, financial characteristics and lastly farm and personal characteristics.

Binary loan characteristics, as shown in Table 1, included account standing (account good (0) and account other (1)), credit history (credit history good (0) and credit history other (1)) and collateral (collateral sufficient (0) and collateral other (1)). Financial characteristics had no binary variables. Multinomial loan characteristics, also shown in Table 1, includes the purpose of loan (short (0), medium (1), and long term (2) loans) while farm and personal characteristics included farm diversification or the number of enterprises on the farm (diverse one (0), diverse two (1), and diverse three or more (2)), associated industry risk (high (2), medium (1) and low risk (0)), and ownership of the enterprise (owner (1), otherwise (0)) as seen in Table 1 below.

Continuous loan characteristics are shown in Table 2 below and consisted of amount of credit required, loan repayment period, period with credit provider (years since first opening of account with institution). Continuous financial characteristics, Table 2, consisted of ratio measures and included solvency (debt to asset ratio, debt to equity ratio), liquidity (current ratio, working capital to gross revenue), profitability (asset turnover, return on assets, return on equity, net farm ratio), and efficiency (production costs, interest expense, and cash flow ratio) measures. Continuous farm and personal characteristics include the age of applicant, years of experience in industry and education/qualification (no education, matric, graduate, post-graduate, and no indication). 
Table 1. Characteristics of respondents in terms of binary and multinomial variables used in the classification of credit applications.

\begin{tabular}{cccc}
\hline Characteristics & Abbreviation Used for Categories & Frequency & Percentage \\
\hline \multirow{3}{*}{ Purpose of loan } & Short term & 45 & $35 \%$ \\
& Medium term & 38 & $30 \%$ \\
& Long term & 45 & $35 \%$ \\
\hline \multirow{2}{*}{ Account standing } & Account good & 111 & $87 \%$ \\
& Account other & 17 & $13 \%$ \\
\hline \multirow{2}{*}{ Credit history } & Credithistgood & 116 & $91 \%$ \\
& Credithistother & 12 & $9 \%$ \\
\hline \multirow{2}{*}{ Collateral } & Collateral sufficient & 125 & $98 \%$ \\
& Collateral other & 3 & $2 \%$ \\
\hline \multirow{2}{*}{ Diversification } & Divers1 & 36 & $28 \%$ \\
& Divers2 & 60 & $47 \%$ \\
& Divers3 & 32 & $25 \%$ \\
\hline \multirow{2}{*}{ Risk } & Highrisk & 26 & $20 \%$ \\
& Mediumrisk & 79 & $62 \%$ \\
\hline \multirow{2}{*}{ Ownership } & Lowrisk & 23 & $18 \%$ \\
\hline \multirow{2}{*}{ Observations } & Owner & 120 & $94 \%$ \\
& Not owner & 8 & $6 \%$ \\
\hline \multirow{2}{*}{ Education } & No education & 2 & $2 \%$ \\
& Matric & 34 & $27 \%$ \\
& Graduate & 75 & $59 \%$ \\
& Postgrad & 13 & $10 \%$ \\
& No indication & 4 & $3 \%$ \\
\hline & & & \\
\hline & & &
\end{tabular}

Table 2. Characteristics of respondents in terms of continuous variables used in the classification of credit applications.

\begin{tabular}{ccccccc}
\hline Characteristic & Abbreviation Used & Unit & Average & Min & Max & STD Dev ${ }^{\S}$ \\
\hline Loan Amount & Amount & ZAR & $5,910,996$ & 0 & $52,000,000$ & $7,741,051$ \\
\hline Loan Period & Period & Months & 84 & 0 & 180 & 64 \\
\hline Years as client & Business & Years & 14 & 0 & 60 & 14 \\
\hline & DTA & Ratio & 0 & 0 & 2 & 0 \\
& DTE & Ratio & 1 & -6 & 32 & 3 \\
Financial & CR & Ratio & 176,520 & 0 & $9,800,000$ & 970,630 \\
characteristics & WCTGR & Ratio & 0 & -2 & 6 & 1 \\
& ATO & Ratio & 0 & 0 & 2 & 0 \\
& ROA & Ratio & 0 & 0 & 2 & 0 \\
& ROE & Ratio & 0 & -10 & 14 & 2 \\
& NETFARMRATIO & Ratio & 0 & 0 & 2 & 0 \\
& PRODCOST & Ratio & 1 & 0 & 5 & 0 \\
ANge & INTEREST & Ratio & 0 & 0 & 1 & 0 \\
\hline Experience & CASHFLOW & Ratio & 1 & 0 & 2 & 0 \\
\hline
\end{tabular}

$\S$ STD Dev indicates the calculated standard deviation for the variable. 
Some research reported on gender [23] and race in the consideration of access to credit [24]. This research, however, did not include these factors as most of the applicants was male. Also, currently, in South Africa, the majority of commercial farming land is owned by white commercial farmers [25]. Elimination of these factors from the study would also ensure that the possibility of discrimination in terms of race and gender was eliminated. A further reason for not including these factors in the research is because applicants cannot change their gender or race to ensure a successful application. The aim of the research is not to determine the factors that exclude applicants from accessing credit, where it would make sense to include these factors as they might have an impact on access to credit as proven in various previous research.

\subsection{Procedures}

The data was analysed using a logistic regression. To eliminate multi-collinearity (structure between the independent variables) a principal component regression (PCR) approach was used to determine the uncorrelated components to be used in the logistic regression. The PCR has been used in previous research by Motsoari et al. [14], while logistic regression has been applied in credit research by several authors including Motsoari et al. [14], Kohansal and Mansoori [26], and Eze et al. [27]. The PCR initially applies a principal component analysis (PCA) to reduce the number of relatable or correlated variables into uncorrelated components, while maintaining variation. The new data set is known as factor scores. Once the new data set has been generated, a logistic regression is performed. The discussion of the procedures is structured to discuss the logistic regression, the estimation of the PCA, and then application of the logistic regression within the PCR framework.

\subsubsection{Logistic Regression}

The logistic regression (LR) model aims to find the relationship between the outcome dependent variable (accept or reject) and a set of categorical and continuous attributes of the credit applicants. The logistic regression is depicted in Equation (1).

$$
\log \left[\frac{p_{i}}{1-p_{i}}\right]=\beta_{0}+\beta_{1} x_{i}+\beta_{2} x_{2}+\ldots+\beta_{n} x_{n}+\varepsilon
$$

Let $p_{i}$ be the probability of the default of an agricultural borrower $i$, and $\beta_{0}$ is the intercept term. $\beta_{i}$ represents the respective coefficient in the linear combination of independent variables $x_{i}$ for $i=1-n$, which includes financial ratios, borrower characteristics and farm characteristics. The dependent variable is the logarithm of the odds, $\log \left[\frac{p_{i}}{1-p_{i}}\right]$ which is the logarithm of the ratio of two probabilities of the outcome of interest [28]. Given the set of independent variables, the probability of a value of one (1) for the dichotomous outcome is shown in Equation (2).

$$
\frac{p_{i}}{1-p_{i}}=\frac{1}{1+e^{-Z}}
$$

where,

$$
Z=\beta_{0}+\beta_{1} x_{i}+\beta_{2} x_{2}+\ldots+\beta_{n} x_{n}+\varepsilon
$$

In credit scoring, the objective of a logistic regression is to determine the conditional probability of a specific observation within a class, given the values of the independent variables of the credit applicant [28]. Due to moderate multi-collinearity $(g=108$ and condition index $=10.43)$ in the data, and to reduce the number of independent variables, a PCA [29] was performed. 


\subsubsection{Principal Component Analysis (PCA)}

This procedure begins with the transformation of original independent variables into standardised variables. The independent variables are standardised as

$$
x_{i}^{s}=\frac{\left(x_{i}-\bar{x}_{i}\right)}{s_{X i}}
$$

where, $x_{i}^{s}$ is the $i$ th standardised independent variable under consideration, $x_{i}$ is the ith independent variable, $\bar{x}_{i}$ refers to the mean of the independent variable, $x_{i}^{s}$ represents the standard deviation of the ith independent variable. The standardised independent variables are needed for the calculation of the principal components (PCs). These PCs are then used in the regression analysis. The regression is done in a logistic framework (Equation (1)); therefore, the dependent variable (outcome) is not transformed to a standardised dependent variable.

The transformed data is used to calculate the eigenvectors of the variables, since the PCs are based on the eigenvectors. Eigenvalues $\varphi_{1}, \varphi_{2} \ldots \ldots, \varphi_{k}$ and the corresponding eigenvectors $v_{j}$ are based on the correlation matrix $C$. Equations (5) and (6) are used to calculate the eigenvectors and eigenvalues.

$$
|C-\varphi I|=0,\left|C-\varphi_{j}\right| v_{j}=0
$$

The eigenvectors $v_{j}$ are arranged to generate a matrix $\mathrm{V}$, depicted in Equation (6). Matrix $V$ is known to be orthogonal as the columns satisfy conditions $v_{i}^{\prime} v_{i}=1$ and $v_{j}^{\prime} v_{i}=0$ for $i \neq j$ :

$$
V=\left[\begin{array}{cccccc}
v_{11} & v_{12} & & \cdot & \cdot & v_{1 k} \\
v_{21} & v_{22} & & \cdot & \cdot & v_{2 k} \\
\cdot & \cdot & \cdot & \cdot & \cdot \\
\cdot & \cdot & \cdot & \cdot & \cdot \\
v_{k 1} & v_{k 2} & \cdot & \cdot & v_{k k}
\end{array}\right]
$$

The calculated eigenvectors are used to select the components, which are included in the regression. Selection of components are based on the Kaiser-Guttman Rule, which states that components with an eigenvalue greater than one (1) should be included in the regression. IBM SPSS statistics 23 was used to determine the eigenvalues and eigenvectors from the original independent variables.

(a) Extracting the principal components (PCs)

The SPSS software extracted a total of 30 PCs, but due to the exclusion criteria, only PCs with eigenvalues greater than one were considered in the remaining procedures [30]. Using the Kaiser-Guttman rule, only 14 PCs were identified and considered in the regression. The 14 components and their eigenvalues are shown in Table 3. The selected 14 PCs explained 78.5\% of the variability in the independent variables.

The next step in the procedure, as mentioned by Khaile [29], was to determine the significance of the PCs. Here a logistic regression model was fitted using the classification (approved or rejected) as the dependent variable. 
Table 3. Eigenvalues, percentage of variance explained and cumulate percentage of the variance explained by the principal components.

\begin{tabular}{cccc}
\hline Principal Components (E) & Eigen Value & \% of Variance & Cumulative $\%$ \\
\hline 1 & 3050 & 10,168 & 10,168 \\
2 & 2484 & 8282 & 18,449 \\
3 & 2350 & 7833 & 26,282 \\
4 & 2228 & 7426 & 33,708 \\
5 & 1850 & 6168 & 39,876 \\
6 & 1693 & 5645 & 45,521 \\
7 & 1552 & 5173 & 50,694 \\
8 & 1417 & 4724 & 55,418 \\
9 & 1349 & 4498 & 59,916 \\
10 & 1230 & 4099 & 64,014 \\
11 & 1174 & 3913 & 67,927 \\
12 & 1120 & 3733 & 71,660 \\
13 & 1026 & 3422 & 75,081 \\
14 & 1021 & 3402 & 78,483 \\
\hline
\end{tabular}

(b) Determining the significance of PCs with a logistic regression

The PC scores $(E)$ were calculated by matrix multiplication of eigenvalues obtained with the standardised variables $\left(X^{s}\right)$ calculated with Equation (4). Equation (7) shows the equation used to calculate the PC scores $(E)$

$$
E=X^{s} V
$$

where, $X^{s}$ is an $n \times k$ matrix of standardised variables from Equation (4). The component scores $(E)$ are calculated in a matrix multiplication product form, with a dimension of $k$ components equal to $k$ independent variables. The evaluations of the PCs are regressed against the original un-standardised dependent variable $\log \left[\frac{p_{i}}{1-p_{i}}\right]$ (originally from Equation (1))

$$
\log \left[\frac{p_{i}}{1-p_{i}}\right]=\beta_{o}^{s}+X^{s} V \beta^{s}+\varepsilon
$$

where the $X^{s} V$ and $\varepsilon$ are independently distributed by zero, $0 \leq \log \left[\frac{p_{i}}{1-p_{i}}\right] \leq 1$, with the limit point $\log \left[\frac{p_{i}}{1-p_{i}}\right]=1$ possessing a positive probability. $\beta_{o}^{s}$ and $\beta^{s}$ are estimated by the OLS model and standardised coefficients for the constant and independent variables respectively. Since the eigenvectors are orthogonal to each other, as defined by the eigenvector matrix $V$ where $V V^{\prime}=\mathrm{I}$, (Equation (8)) is transformed into the form.

$$
\log \left[\frac{p_{i}}{1-p_{i}}\right]=\beta_{o}^{s}+X^{s} V V^{\prime} \beta^{s}+\varepsilon
$$

or

$$
\log \left[\frac{p_{i}}{1-p_{i}}\right]=\beta_{o}^{s}+E \rho+\varepsilon
$$

where, $E=X^{s} V$ and $\rho=V^{\prime} \beta^{s}$. $\rho$ refers to the $\ell \times \ell$ vector of the new coefficients that are related to the $\ell$ components. The labelled standard errors of the estimated coefficients $\rho$ are signified by a $\ell \times 1$ vector, which is computed in Equation (11) [31,32]

$$
\operatorname{Var}(\hat{\rho})=\delta^{2}\left(E^{\prime} E\right)^{-1}=\hat{\delta} \operatorname{diag}\left(\varphi_{1}^{-1}, \varphi_{2}^{-1} \ldots \ldots, \varphi_{\ell}^{-1}\right)
$$

The $\delta^{2}$ refers to the variance of the residuals computed in Equation (8). The elimination of PCs do not change the magnitude of the variance [31]. The elimination of one or more PC will eventually decrease the total variance, creating an improved model. The removal of PCs are based on the 
significance determined by the regression results [32]. Should the PCs be removed due to insignificance, then Equation (10), can be reformulated to use $k-r$ components as seen in Equation (12).

$$
\varphi=\beta_{o}^{s}+E_{k-r} \rho_{k-r}+\varepsilon^{0}
$$

The 0 symbol on $\varepsilon^{0}$ in Equation (12), is used to differentiate from the $\varepsilon$ in Equation (10). The residual in Equation (12) varies as the vectors of the coefficients have been reduced to $k-r$ components.

The results of the logistic regression are given in Table 4 . Table 4 indicates that the intercept and six of the components are significant $(p<10 \%)$. The interpretation of the components is not essential in the discussion of the objective.

Table 4. Significance of the principal components in the credit classification process.

\begin{tabular}{cccc}
\hline Variable & Coefficients & Standard Error & $p$-Value \\
\hline Intercept & 2.705 & 0.864 & $0.002^{*}$ \\
ZPC 1 & 1.487 & 0.495 & $0.003^{*}$ \\
ZPC 2 & -0.594 & 0.354 & $0.093^{* * *}$ \\
ZPC 3 & 0.466 & 0.594 & 0.433 \\
ZPC 4 & -1.256 & 0.614 & $0.041^{* *}$ \\
ZPC 5 & 3.513 & 0.999 & $0.000^{*}$ \\
ZPC 6 & -0.054 & 0.541 & 0.921 \\
ZPC 7 & 1.192 & 0.784 & 0.128 \\
ZPC 8 & -1.681 & 0.655 & $0.010^{*}$ \\
ZPC 9 & 0.427 & 0.827 & 0.605 \\
ZPC 10 & 1.680 & 0.962 & $0.081^{* * *}$ \\
ZPC 11 & 0.610 & 1.177 & 0.604 \\
ZPC 12 & -0.029 & 0.675 & 0.966 \\
ZPC 13 & -0.599 & 0.700 & 0.392 \\
ZPC 14 & -1.552 & 1.433 & 0.279
\end{tabular}

The ${ }^{* * *}, * * *$ indicates significance of $1 \%, 5 \%$ and $10 \%$ respectively. ZPC indicates the estimated principal component.

The final step in the procedure is to estimate the significance of each individual variable from the PCs. One of the advantages of the PCR technique is that it has the ability to estimate all the hypothesised independent variables [29]. The $\beta^{s}$ coefficients, from Equation (12), and the standard errors-squared for significant components are extracted from the logistic regression.

(c) Calculating the un-standardised dependent variables

The retained PCs are then transformed into standardised independent variables by making use of Equation (13).

$$
\begin{aligned}
& b_{p c}^{s}=V_{k-r} \hat{P_{k-r}}
\end{aligned}
$$

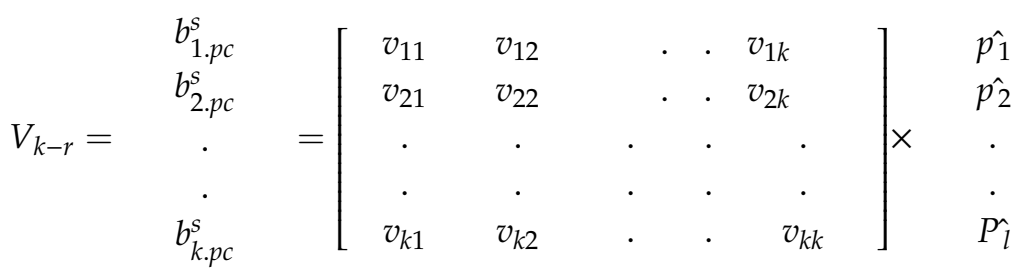

where $V_{k-r}$ is the matrix of eigenvectors with retained PCs. $\hat{\rho_{k-r}}$ is a vector of coefficients (apart from the intercept) of $\rho_{i}$ in Equation (12), and $b_{p c}^{s}$ is a vector of coefficients (except for the intercept) of parameters in vector $\beta^{s}$ estimated in Equation (8). The variance of the PC estimators in the form of standardised variables are computed by

$$
\operatorname{Var}\left(b_{p c}^{s}\right)=\vartheta_{\ell}^{s} K^{S}
$$

The $\vartheta_{\ell}^{s}$ refers to the squares of the eigenvector elements of $V_{\ell}^{s}$ (Equation (6)) and $K^{S}$ indicates the squares of the elements of the matrix of standard errors of the coefficient matrix $\rho$ in Equation (10). 
The corresponding standard errors for the estimators of PCs of standardised variables are calculated in Equation (16).

$$
\text { s.e. }\left(b_{p c}^{s}\right)=\operatorname{Var}\left[\left(b_{p c}^{s}\right)\right]^{\frac{1}{2}}
$$

The standardised variables $b_{p c}^{s}$ are transformed back to natural un-standardised variables $b_{i, p c}$ of $X^{i}$. The results of the procedure are given by

$$
b_{i, p c}=\frac{b_{i, p c}^{s}}{1 / S_{x i}} ; i=1,2 \ldots \ldots k
$$

and

$$
b_{o, p c}=b_{o, p c}^{s}-\frac{b_{1, p c}^{s} \bar{x}_{1}}{S_{x 1}}-\frac{b_{2, p c}^{s} \bar{x}_{2}}{S_{x 2}}-\ldots-\frac{b_{k, p c}^{s} \bar{x}_{k}}{S_{x k}}
$$

where $S_{x i}$ is the standard deviation of the $i^{\text {th }}$ original variable $X_{i}$ and $b_{o, p c}^{s}, b_{1, p c^{\prime}}^{s} b_{2, p c^{\prime}}^{s} \ldots \ldots b_{k, p c}^{s}$ are coefficients of the standardised variables. Since the original un-standardised dependent variable (decision) is used in the logistic regression when estimating the significance of the PC, it then follows that the $b_{i, p c}$ can be correctly calculated when the standard deviation $S_{x i}$ is calculated by $\frac{1}{S_{x i}}$ as indicated in Equation (17).

\section{Results}

The results from the logistic PC procedure are given in Table 5. It is important to note that the coefficients and significance in Table 5 do not indicate that there is a difference in importance between the variables. The results provide an indication of the influence of the variation observed for each variable in relation to the variation observed in the classification, specific to the present case. By implication, the model identifies the variables that are more likely to have an influence on applications being accepted or rejected.

The results shown in Table 5 indicate that 15 of the 30 variables are significant at a $10 \%$ level. These variables include loan amount, years of business with bank, account standings, credit history, collateral, production costs, interest expense ratio, number of enterprises on the farm (diverse two, diverse three and more), ownership of the farming business, age, experience, and education level (no education, post graduate, and no indication). From the results, it can be seen that factors from all three categories-loan, financial, as well as farm and personal characteristics-are considered in the granting of credit to agricultural applications.

In terms of loan characteristics, the results indicate that larger loan-amount applications may be less likely to be classified as approved $(p<0.1)$. The behaviour of the applicant and the relationship between the applicant and the financial institution may also have an influence on the possible classification of the applicant [12]. This is indicated by the negative influence of account standing and credit history of the applicant $(p<0.01)$, research should, therefore include the credit providers assessment on the clients account standings as opposed to just an indication whether savings exists. Motsoari et al. [14] also mention that a positive relationship is expected between repayment record (credit record) and access to credit, meaning that a good record would increase the changes of access to credit in the future. Apart from an overall credit history, financial institutions also look at the years of business of their clients. This fact is also illustrated in the results where more loyal clients of the financial institution (clients who held accounts or were with the bank for longer periods) are more likely to be classified in the approved category (Business, $p<0.1$ ). These findings is similar to the findings of Awunyo-Vitor et al. [23] and provide a wider indication of factors such as period of being a client as opposed to only having a good credit record or savings. The number of years with the institution should thus be considered in future research on access to credit by farmers. Research has shown that an additional year of savings with a formal lender could reduce the chance that an application be rejected [23]. Savings and loyalty to the lender is thus not only important to be possibly more successful with loan applications as mentioned by 
Awunyo-Vitor et al. [23]. The authors further mention that savings can be used as collateral for loans. These results illustrate that a good, long-standing relation with the financial institution, repaying loans, and investing money in their facilities (savings) and doing business by using their account facilities, do provide an advantage when applications are made for loans.

Table 5. Determinants in the classification of loan applications (standardised data).

\begin{tabular}{|c|c|c|c|}
\hline Variables & Coefficient & Standard Error & $p$-Value \\
\hline \multicolumn{4}{|l|}{ Loan Characteristics } \\
\hline Medium term & -0.3800 & 0.3595 & 0.29 \\
\hline Long term & 0.1588 & 0.2622 & 0.55 \\
\hline Loan Amount & $-0.3750^{* * *}$ & 0.1933 & 0.06 \\
\hline Loan Period & -0.0759 & 0.2929 & 0.80 \\
\hline Business & $0.4213^{* * *}$ & 0.2408 & 0.08 \\
\hline Account standing & $-1.7434 *$ & 0.3794 & 0.00 \\
\hline Credit history & $-2.3272 *$ & 0.4943 & 0.00 \\
\hline Collateral & $-1.5376^{*}$ & 0.3868 & 0.00 \\
\hline \multicolumn{4}{|c|}{ Financial Characteristics } \\
\hline DTA & 0.0216 & 0.4404 & 0.96 \\
\hline DTE & -0.1861 & 0.2898 & 0.52 \\
\hline CR & 0.0818 & 0.1675 & 0.63 \\
\hline WCTGR & -0.1747 & 0.1940 & 0.37 \\
\hline ATO & 0.3481 & 0.3265 & 0.29 \\
\hline ROA & 0.4325 & 0.3139 & 0.17 \\
\hline ROE & -0.2131 & 0.2869 & 0.46 \\
\hline NETFARMRATIO & -0.4421 & 0.3637 & 0.23 \\
\hline PRODCOST & $0.7368^{* *}$ & 0.3593 & 0.04 \\
\hline INTEREST & $-1.0388 *$ & 0.2846 & 0.00 \\
\hline CASHFLOW & -0.2615 & 0.3630 & 0.47 \\
\hline \multicolumn{4}{|c|}{ Farm and Personal Characteristics } \\
\hline Diverse2 & $-1.3204 *$ & 0.3936 & 0.00 \\
\hline Diverse3 & $1.0748 *$ & 0.2950 & 0.00 \\
\hline High risk & 0.0089 & 0.1255 & 0.94 \\
\hline Medium risk & 0.3290 & 0.2297 & 0.16 \\
\hline Owner & $1.6524 *$ & 0.3180 & 0.00 \\
\hline Age & $0.4625^{* * *}$ & 0.2548 & 0.07 \\
\hline Experience & $0.6472 * *$ & 0.2824 & 0.02 \\
\hline No education & $0.5426^{* *}$ & 0.2274 & 0.02 \\
\hline Graduate & 0.0753 & 0.4644 & 0.87 \\
\hline Postgraduate & $0.9381 * *$ & 0.4038 & 0.02 \\
\hline No indication & $-0.9777 *$ & 0.3017 & 0.00 \\
\hline
\end{tabular}

The $^{*}, * *, * * *$ indicates significance of $1 \%, 5 \%$, and $10 \%$ respectively.

Collateral is an important factor to be considered in loan applications, as this is the security provided to the institution in default situations. One expects collateral to be significant in the classification of applications to ensure that enough security is provided. Previous research has also considered this aspect in different forms, especially land tenure, because the applicant owns the land [14]. This is also reflected in the results where applicants in the 'other than good' category are less likely to be classified in the approved category $(p<0.01)$. The result is a good indication that the credit institution has to ensure that enough security is provided to cover the loan, or total debt exposure, should the client default. This confirms the thought of Ghosh et al. [33] that collateral is a prerequisite for formal institutions and that resource poor farmers may therefore struggle to access credit capital. However, this result is contradictory to research of Motsoari et al. [14] who found that ownership of land (providing security) has a negative relationship with access to credit. The authors provide a possible reason for their finding in that most of the borrowers participated in government programs, which does not require ownership (security) for approving loans. These results will have 
quite a serious impact on smaller and emerging farmers who do not necessarily have the resources to provide collateral or security for a new loan. Especially when there are no specific credit products from institutions aimed at smallholder and/or emerging farmers whereby collateral is provided or considered in different forms.

Previous research (for example Ogundeji et al. [21]) found that keeping records do have an impact on accessing credit. It can, however, be argued that the keeping of records is only the initial requirement and that accurate and reliable information from the financial statements do also have an impact on loan applications. These could be in terms of financial analysis that are traditionally used in credit analysis. The research explored this by including a ratio analysis calculated from the financial information provided rather than just asking, whether financial records were kept. The significant interest expense ratio $(p<0.01)$ of the farm indicates that the higher the interest expense ratio, the less likely an application is to be approved. Considering that higher interest payments are an indication of larger levels of debt, this result could be interpreted as an indication that the debt levels of the applicant is already high. As a result, the farmer may be taking on too much debt when the current application is considered. This result is similar to previous indication by Ogundeji et al. [21] where it was found that higher interest rates are negatively related to farmers accessing loans for financing institutions. The production costs ratio $(p<0.05)$ has a positive influence on the likelihood of being classified as approved. This is a rather strange observation, since a higher production cost ratio indicates that a greater percentage of the gross farm income has been spent on production costs, thus leading to lower net farm income. In general, the results do indicate that keeping record do assist in accessing loans, but that the financial statements are used for purposes more than just being able to prove that the financial statements exists and for actual analysis of performance and repayment ability of the applicant.

In terms of the farm and personal characteristics, the number of enterprises influenced the possibility to be classified approved. Research on small enterprises by Nikaido et al. [34] found that enterprises with diversified activities are more likely to receive formal credit. Diversified activities were also explored in the research with Diverse 1 used as the base category where applicants had only one enterprise, relying on one enterprise (no diversification). Interestingly, applicants with two enterprises $(p<0.01)$ were less likely to be classified as approved compared to a single enterprise (Diverse 1). On the other hand, applicants with three or more enterprises $(p<0.01)$ were more likely to be classified as accepted than applicants with one enterprise (Diverse 1). The results do indicate that it is important to consider more than just the enterprises of the farming business, but also the number of enterprises. The more enterprises in the business or farming business in this case, the more the risk may be spread to ensure potential income and be more resilient in difficult times [34]. There is, however, a chance that this may also lead to the possibility that one enterprise may receive preferential attention over another, leading to a potential decline in the performance of the neglected enterprise, resulting in higher risk and potential losses. The result may be an indication that diversification is a method by which risk can be spread, and the results indicated that spreading the risk to more than two enterprises or alternatively, to be focused on one enterprise, may be beneficial in loan applications. This should, however, be further investigated in future research to have a better understanding on the impact of the number of enterprises.

Differences in personal factors, which influenced the classification of applicants included ownership, age, experience, and education. Ownership $(p<0.01)$, age $(p<0.1)$ and experience $(p<0.05)$ contributed positively to being classified in the approved category. In terms of education, the result indicated that where there was no indication that education level had a negative influence on being classified in the approved category $(p<0.01)$ compared to applicants that had a Grade 12 (matric) education. This result is expected since evidence has shown that education has a very important role as part of human capital [34,35]. 


\section{Conclusions}

The aim of this research was to determine the influence of different factors used in evaluating loan applications in the agricultural sector by a formal credit institution. Results from the principal component logistic regression indicated that factors resulting in successful applications included older more experienced farmers, sufficient collateral, years of business with the credit provider, acceptable credit history, smaller loan amounts, lower levels of debt (lower interest expense ratio), higher production cost ratios and enterprise diversification. These factors were classified into two broad categories. The first was small loans; smaller loan amounts were more likely to be awarded. The second category was the ability of the applicant to carry or manage risk, and thereby their ability to repay the loan. One of the risks faced by credit providers is the default of an applicant. As a result, the credit provider would like to ensure that sufficient collateral is available, and that the current debt levels are within acceptable ranges. Historical repayment performance is also considered to ensure that the applicant does not have a history of default. From the research, it is found that information such as the period the applicant has been a client of the institution, account standings, and number of enterprise diversification should be considered in future research on farmers access to credit. It is thus not only collateral and a good credit history, but also staying with your banking institution for longer periods and maintaining good account standings, could assist in positive outcomes in credit applications. Diversification of farming enterprises is a well-known strategy to manage risk. As a result, applicants with different diversification strategies have different loan application outcomes. The results indicate that applicants who focussed on one enterprise (Diverse 1) were more likely to be approved for a loan than an applicant with two farming enterprises. Applicants with three or more farming enterprises were more likely to be successful in their application compared to farming with a single enterprise. It can therefore be argued that applicants who diversify in more than two enterprises are more likely to be successful in loan applications. A possible explanation could be that the farming business has moved from an operation with a single enterprise to a more diversified farming enterprise. Thereby, the risk is spread and consequently the probability of defaulting on the loan is possibly minimised. However, this is a matter that requires further investigation in the future.

The conclusion is that applicants must trade-off the loan amount applied for against the size of the loan amount needed, the current debt structure and repayment ability to ensure affordability of the loan over the loan duration. Advice to smallholder farmers would be to ensure that they are able to provide information on repayment ability with strong financial evidence instead of merely providing proof of existing financial statements. The research also provides a picture of credit applications without the assistance of receiving any subsidies from the government, indicating that the farmers only have their farming businesses or other non-farm income sources and no subsidies as sources of income. Countries that are thus experiencing reduction or possible removal of subsidies could learn from the South African experience. Future research should investigate the factors that affect an applicant's ability to repay loans as used in credit evaluations by expanding the number of credit providers (financial institutions) and total number of applicants considered in the analysis. Further consideration can also be given to differences in credit granting between branches, farming enterprises, and economical scale of farms in relation to one specific financial institution compared with others.

Author Contributions: Conceptualization, J.I.F.H., D.A.B., and H.J.; Formal analysis, J.I.F.H., D.A.B., H.J., and N.M.; Funding acquisition, J.I.F.H.; Investigation, J.I.F.H. and D.A.B.; Methodology, J.I.F.H., D.A.B., H.J., and N.M.; Project administration, J.I.F.H.; Supervision, J.I.F.H. and H.J.; Validation, D.A.B.; Writing-Original draft, J.I.F.H. and D.A.B.; Writing-review and editing, J.I.F.H., D.A.B., H.J., and N.M.

Funding: This work is based on the research supported in part by the National Research Foundation of South Africa for the grant, unique grant no. 94132. Any opinion, finding and conclusion or recommendation expressed in this material is that of the author(s) and the NRF does not accept any liability in this regard.

Conflicts of Interest: The authors declare no conflict of interest. The funders had no role in the design of the study; in the collection, analyses, or interpretation of data; in the writing of the manuscript, or in the decision to publish the results. 


\section{References}

1. Kumara, A.; Singh, K.M.; Sinha, S. Institutional credit to agriculture sector in India: Status, performance and determinants. Agric. Econ. Res. Rev. 2010, 23, 253-264.

2. Katchova, A.L.; Barry, P.J. Credit risk models and agricultural lending. Am. J. Agric. Econ. 2005, 87, $194-205$. [CrossRef]

3. September, M.T. Credit Risk Management: Loans to High Risk Agricultural Clients in Central South Africa. Master's Thesis, University of the Free State, Bloemfontein, South Africa, 2010.

4. Spierenburg, M. Living on other people's land; Impacts of farm conversions to game farming on farm dwellers' abilities to access land in the eastern cape, South Africa. Soc. Nat. Resour. 2019. [CrossRef]

5. Department of Agriculture, Forestry \& Fisheries (DAFF). Abstract of Agricultural Statistics 2018; Department of Agriculture, Forestry \& Fisheries: Pretoria, South Africa, 2018.

6. Qwabe, N.P. Lending to Small-Scale Farmers in South Africa: A Case for Best Practices in Formal Institutions. Master's Thesis, University of Pretoria, Pretoria, South Africa, 2014.

7. Department of Agriculture, Forestry \& Fisheries (DAFF). Trends in the Agricultural Sector 2015; Department of Agriculture, Forestry \& Fisheries: Pretoria, South Africa, 2016; ISSN 1025-5028.

8. Salame, E. Applying Data Mining Techniques to Evaluate Applications for Agricultural Loans. Ph.D. Thesis, University of Nebraska, Lincoln, NE, USA, 2011.

9. BearingPoint. USAID-Funded Economic Governance II Project. Available online: http://pdf.usaid.gov/ pdfdocs/Pnadq084.pdf (accessed on 29 March 2016).

10. Marqués, A.I.; García, V.; Sánchez, J.S. A literature review on application of evolutionary computing to credit scoring. J. Oper. Res. Soc. 2013, 64, 1384-1399. [CrossRef]

11. Abdou, A.; Pointon, J.; El-Masry, A. Neural nets versus conventional techniques in credit scoring in Egyptian banking. Expert Syst. Appl. 2008, 35, 1275-1292. [CrossRef]

12. Limsombunchai, V.; Gan, C.; Lee, M. An analysis of credit scoring for agricultural loans in Thailand. Am. J. Appl. Sci. 2005, 2, 1198-1205. [CrossRef]

13. Spio, K. The Impact and Accessibility of Agricultural Credit: A Case Study of Small-Scale Farmers in the Northern Province of South Africa. Ph.D. Thesis, University of Pretoria, Pretoria, South Africa, 2002.

14. Motsoari, C.; Cloete, P.C.; van Schalkwyk, H.D. An analysis of factors affecting access to credit in Lesotho's smallholder agricultural sector. Dev. South. Afr. 2015, 32, 592-602. [CrossRef]

15. Guyon, I.; Elisseeff, A. An introduction to variable and feature selection. J. Mach. Learn. Res. 2003, 3, 1157-1182.

16. Bolton, C. Logistic Regression and Its Application in Credit Scoring. Master's Thesis, University of Pretoria, Pretoria, South Africa, 2009.

17. West, D. Neural network credit scoring models. Comput. Oper. Res. 2000, 27, 1131-1152. [CrossRef]

18. Bandyopahay, A. Credit Risk Models for Managing Bank's Agricultural Loan Portfolio; National Institute of Bank Management: Pune, India, 2007.

19. Kim, J. A Credit Risk Model for Agricultural Loan Portfolios under the New Basel Capital Accord. Ph.D. Thesis, University of Texas, Austin, TX, USA, 2005.

20. Henning, J.I.F.; Jordaan, H. Determinants of financial sustainability for farm credit applications-A Delphi Study. Sustainability 2016, 8, 77. [CrossRef]

21. Ogundeji, A.A.; Donkor, E.; Motsoari, C.; Onakuse, S. Impact of access to credit on farm income: Policy implications for rural agricultural development in Lesotho. Agrekon 2018, 57, 152-166. [CrossRef]

22. Henning, J.I.F.; Jordaan, H. Investigating factors considered in agricultural credit applications, what are currently considered by commercial bank? In Proceedings of the 20th International Farm Management Congress, Quebec City, QC, Canada, 12-17 July 2015; pp. 138-145.

23. Awunyo-Vitor, D.; Mahama Al-Hassan, R.; Bruce Sarpong, D.; Egyir, I. Agricultural credit rationing in Ghana: What do formal lenders look for? Agric. Financ. Rev. 2014, 74, 364-378. [CrossRef]

24. Oladele, I.; Ward, L. Determinants of loan repayment patterns among Micro Agricultural Financial Institution of South Africa beneficiaries in North West Province, South Africa. J. Agric. Environ. Int. Dev. 2016, 110, 365-376. 
25. Vink, N.; Kirsten, J. Principles and Practice for Successful Farmland Redistribution in South Africa. A Keynote Paper Presented at a Two-Day National Conversation on: Resolving the Land Question: Land Redistribution for Equitable Access to Land in South Africa. Working Paper 57. Institute for Poverty, Land and Agrarian Studies (PLAAS), 2019. Available online: http://repository.uwc.ac.za/bitstream/handle/10566/ 4653/wp_57_successful_farmland_redistribution_south_africa.pdf?sequence=1\&isAllowed=y (accessed on 14 October 2019).

26. Kohansal, M.R.; Mansoori, H. Factors affecting on loan repayment performance of farmers in Khorasan-Razavi province of Iran. Presented at the Conference on International Research and Food Security, Natural Resource Management and Rural Development, Tropentag, University of Hamburg, Hamburg, Germany, 6-8 October 2009; Available online: http://www.tropentag.de/2009/abstracts/full/264 (accessed on 6 September 2018).

27. Eze, C.C.; Ibekwe, U.C.; Korie, O.C. Women's accessibility to credit from selected commercial banks for poverty reduction in South East Nigeria. Presented at the International Farm Management 17th Congress, Bloomington/Normal, Washington, IL, USA, July 2009; pp. 674-689.

28. Lee, T.S.; Chiub, C.C.; Luc, C.J.; Che, I.F. Credit scoring using the hybrid neural discriminant technique. Expert Syst. Appl. 2002, 23, 245-254. [CrossRef]

29. Khaile, P.M.E. Factors Affecting Technical Efficiency of Small-Scale Raisin Producers in Eksteenskuil. Master's Thesis, University of the Free State, Bloemfontein, South Africa, 2012.

30. Jordaan, H. New Institutional Economic Analysis of Emerging Farmers' Food Value Chains. Ph.D. Thesis, University of the Free State, Bloemfontein, South Africa, 2012.

31. Fekedulegn, B.D.; Colbert, J.J.; Hicks, R.R., Jr.; Schuckers, M.E. Coping with Multicollinearity: An Example on Application of Principal Components Regression in Dendroecology; Research Paper NE-721; USDA Forest Service: Washington, DC, USA, 2002.

32. Magingxa, L.L. Smallholder Irrigators and the Role of Markets: A New Institutional Approach. Ph.D. Thesis, University of the Free State, Bloemfontein, South Africa, 2006.

33. Ghosh, P.; Mookherjee, D.; Ray, D. Credit rationing in developing countries: An overview of the theory. In Development Economics; Mookherjee, D., Ray, D., Eds.; Blackwell: London, UK, 1999.

34. Nikaido, Y.; Pais, J.; Sarma, M. What hinders and what enhances small enterprises' access to formal credit in India? Rev. Dev. Financ. 2015, 5, 43-52. [CrossRef]

35. Davidsson, P.; Honig, B. The role of social and human capital among nascent entrepreneurs. J. Bus. Ventur. 2003, 18, 301-331. [CrossRef]

(C) 2019 by the authors. Licensee MDPI, Basel, Switzerland. This article is an open access article distributed under the terms and conditions of the Creative Commons Attribution (CC BY) license (http://creativecommons.org/licenses/by/4.0/). 